\author{
Military Technical College \\ Kobry El-Kobbah, \\ Cairo, Egypt
}

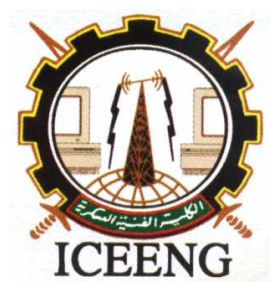

\author{
$6^{\text {th }}$ International Conference \\ on Electrical Engineering \\ ICEENG 2008
}

\title{
Power density comparison for various types of non-slotted double-sided axial flux PM motors
}

\author{
By \\ S.A.Gholamian * \\ M. Ardebili* \\ K. Abbaszadeh *
}

\section{Abstract:}

There are two topologies for non-slotted double-sided axial flux PM (AFPM) motors. The stator of the non-slotted AFPM machine is realized by non-slotted tape wound core with AC polyphase air gap windings and the rotor structure is formed by axially magnetized fan-shaped surface mounted Neodymium Iron Boron $(\mathrm{NdFeB})$ permanent magnets. Selecting an AFPM motors with high power density is an important parameter in applications. So, comparison of power density between different topologies of double-sided AFPM motors seems to be necessary.

In this paper, the sizing equations of axial flux non-slotted one-stator-two-rotor (TORUS) and two-stator-one-rotor (AFIR) type PM motors is presented and comparison of the TORUS and AFIR topologies in terms of power density is illustrated. Finally a high power non-slotted double-sided AFPM motor is introduced in the paper.

\section{Keywords:}

Axial flux PM motors (AFPM), power density.

* Electrical Engineering Department of K.N. Toosi

University of Technology Tehran, Iran 


\section{Introduction:}

Double-sided axial flux PM motors (AFPM) are the most promising and widely used types. AFPMs (commonly called disc machines) are synchronous machines. In conventional machines, the air gap flux density has normally radial direction; in AFPMs, the air gap flux density presents mainly axial direction. In general, AFPMs exhibit an axial length much smaller than the length of a conventional motor of the same rating [1].

There are two topologies for non-slotted double-sided AFPM motors. These topologies are axial flux non-slotted one-stator-two-rotor (TORUS) and two-stator-one-rotor (AFIR) type PM motors. Two AFPM motors and their acronyms are selected TORUSNS (Axial flux non-slotted external rotor internal stator PM stator) and AFIR-NS (Axial flux non-slotted internal rotor external stator PM motor) for detailed analysis. The stator of the non-slotted AFPM motors are realized by non-slotted tape wound core with AC polyphase air gap windings that are back-to-back wrapped around the stator core. The rotor structure is formed by axially magnetized surface mounted Neodymium Iron Boron $(\mathrm{NdFeB})$ permanent magnets and shaft. Detailed views of the stator and rotor structures of the TORUS-NS and AFIR-NS motor are given in figure (1). The portions between the windings are assumed to be filled with epoxy resin as in all non-slotted structures in order to increase the robustness of the structure and provide better conductor heat transfer. Moreover, the radial portions of the air gap windings are used for the torque production [3-4].

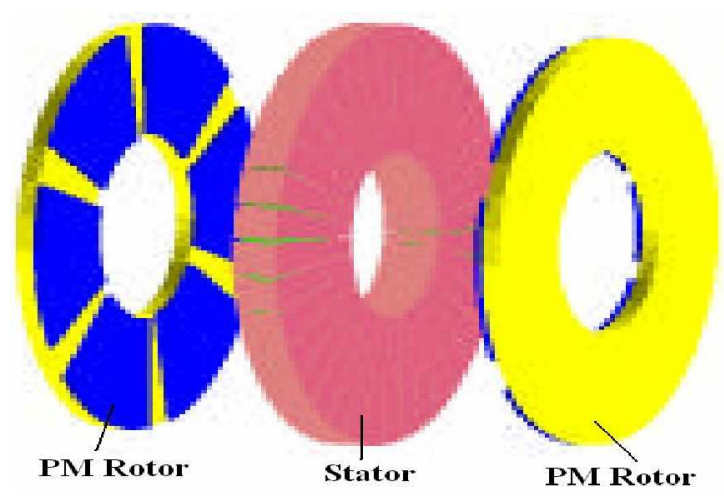

(a)

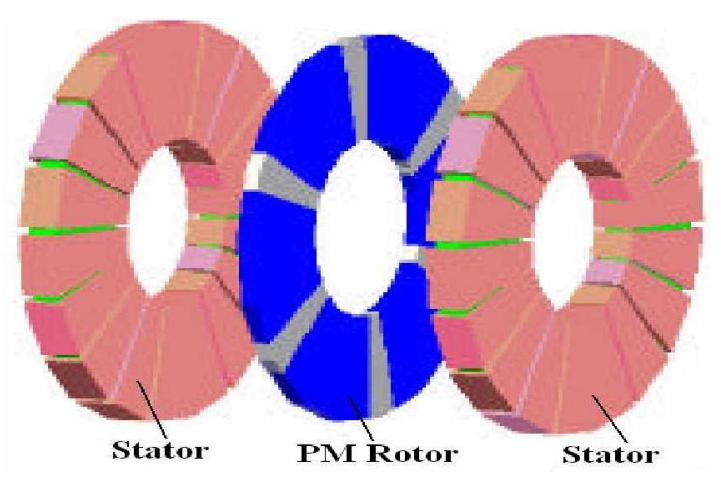

(b)

Figure (1): Axial flux non-slotted (a) one-stator-two-rotor TORUS-NS type [4] (b) two-stator-one-rotor AFIR-NS type [3]

Flux directions of both AFIR and TORUS non-slotted topologies at the average diameter in $2 \mathrm{D}$ are also shown in figure. $2 \mathrm{a}$ and $2 \mathrm{~b}$. 


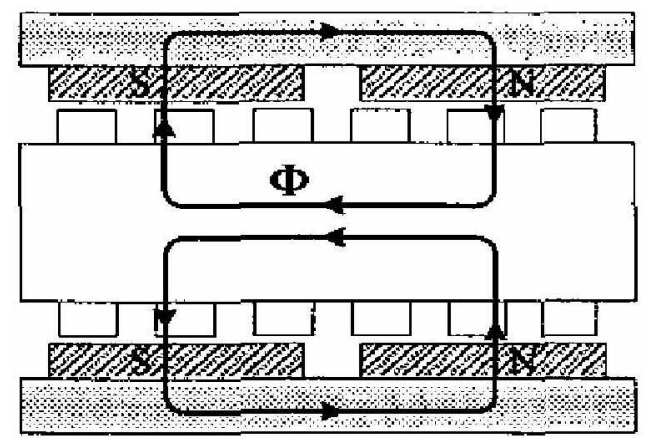

(a)

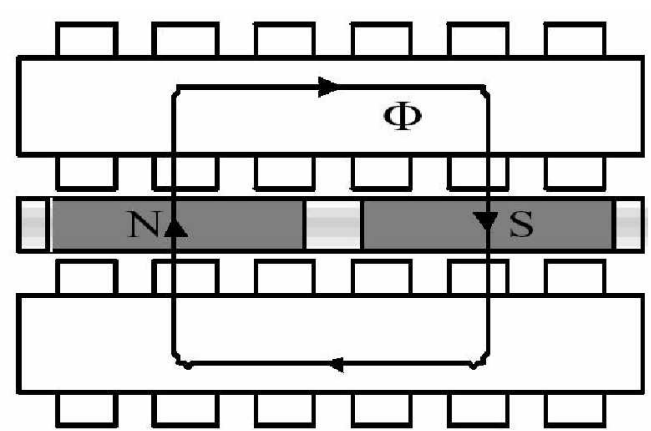

(b)

Figure (2): One pole pair of the (a) TORUS-NS [4] (b) AFIR-NS [3]

Selecting a double-sided AFPM motors with high power density is an important parameter, especially in electrical vehicle applications. So, comparison of power density between different topologies of double-sided AFPM motors seems to be necessary. Increasing the air gap length, maximum power density will change in AFPM motors. These changes are not the same in different topologies. Maximum power density of TORUS-NS is higher than AFIR-NS in large air gap length.

In Section II, the generalized sizing approach for TORUS-NS and AFIR-NS types PM motors is briefly discussed. Then, some results of comparisons of the TORUS-NS and AFIR-NS topologies in terms of power density are illustrated in Section III. The conclusions are given in Section IV.

\section{Sizing equations of AFPM motors:}

In general, if stator leakage inductance and resistance are neglected, the output power for any electrical machine can be expressed as

$\mathrm{P}_{\text {out }}=\eta \frac{\mathrm{m}}{\mathrm{T}} \int_{0}^{\mathrm{T}} \mathrm{e}(\mathrm{t}) \cdot \mathrm{i}(\mathrm{t}) \mathrm{dt}=\mathrm{mK}_{\mathrm{p}} \eta \mathrm{E}_{\mathrm{pk}} \mathrm{I}_{\mathrm{pk}}$

where

$e(t)$ and $E_{p k}$ are phase air gap EMF and its peak value, $i(t)$ and $I_{p k}$ are phase current and the peak phase current, $\eta$ is machine efficiency, $m$ is number of phases of the machine and $T$ is period of one cycle of the EMF[2-4].

The quantity $K_{p}$ is termed the electrical power waveform factor and defined as

$\mathrm{K}_{\mathrm{p}}=\frac{1}{\mathrm{~T}} \int_{0}^{\mathrm{T}} \frac{\mathrm{e}(\mathrm{t}) \times \mathrm{i}(\mathrm{t})}{\mathrm{E}_{\mathrm{pk}} \times \mathrm{I}_{\mathrm{pk}}} \mathrm{dt}=\frac{1}{\mathrm{~T}} \int_{0}^{\mathrm{T}} \mathrm{f}_{\mathrm{e}}(\mathrm{t}) \cdot \mathrm{f}_{\mathrm{i}}(\mathrm{t}) \mathrm{dt}$

where

$f_{e}(t)=e(t) / E_{p k}$ and $f_{i}(t)=i(t) / I_{p k}$ are the expressions for the normalized EMF and current waveforms. In order to indicate the effect of the current waveform, a definition for 
current waveform factor, $K_{i}$, is also useful,

$\mathrm{K}_{\mathrm{i}}=\frac{\mathrm{I}_{\mathrm{pk}}}{\mathrm{I}_{\mathrm{rms}}}=\left[\frac{1}{\mathrm{~T}} \int_{0}^{\mathrm{T}}\left(\frac{\mathrm{i}(\mathrm{t})}{\mathrm{I}_{\mathrm{pk}}}\right)^{2} \mathrm{dt}\right]^{-0.5}$

Where, $I_{r m s}$ is the rms value of the phase current. The peak value of the phase air gap EMF for AFPM in (1) is given by:

$\mathrm{E}_{\mathrm{pk}}=\mathrm{K}_{\mathrm{e}} \mathrm{N}_{\mathrm{ph}} \mathrm{B}_{\mathrm{g}} \cdot \frac{\mathrm{f}}{\mathrm{p}} \cdot\left(1-\lambda^{2}\right) \mathrm{D}_{\mathrm{o}}^{2}$

Where, $K_{e}$ is the EMF factor which incorporates the winding distribution factor $K_{w}$ and the per unit portion of the total air gap area spanned by the salient poles of the machine (if any), $N_{p h}$ is the number of turn per phase, $B g$ is the flux density in the air gap, $f$ is the converter frequency, $p$ is the machine pole pairs, $\lambda$ is the diameter ratio for AFPM defined as $D_{i} / D_{o}, D_{o}$ is the diameter of the machine outer surface, $D_{i}$ is the diameter of the machine inner surface. The peak phase current in (1) is given by:

$\mathrm{I}_{\mathrm{pk}}=\mathrm{A} \pi \mathrm{K}_{\mathrm{i}} \frac{1+\lambda}{2} \cdot \frac{\mathrm{D}_{\mathrm{o}}}{2 \mathrm{~m}_{1} \mathrm{~N}_{\mathrm{ph}}}$

Where, $m_{l}$ is number of phases of each stator and $A$ is the electrical loading. Combining (1) through (5), the general purpose sizing equations take the following form for AFPM.

$\mathrm{P}_{\text {out }}=\frac{\mathrm{m}}{\mathrm{m}_{1}} \frac{\pi}{2} \mathrm{~K}_{\mathrm{e}} \mathrm{K}_{\mathrm{p}} \mathrm{K}_{\mathrm{i}} \mathrm{AB} \mathrm{B}_{\mathrm{g}} \eta \frac{\mathrm{f}}{\mathrm{p}}\left(1-\lambda^{2}\right)\left(\frac{1+\lambda}{2}\right) \mathrm{D}_{\mathrm{o}}^{3}$

The machine power density for the total volume can be defined as

$\mathrm{P}_{\text {den }}=\frac{\mathrm{P}_{\text {out }}}{\frac{\pi}{4} \mathrm{D}_{\text {tot }}^{2} \mathrm{~L}_{\text {tot }}}$

Where, $D_{\text {tot }}$ is the total machine outer diameter including the stack outer diameter and the protrusion of the end winding from the iron stack in the radial direction, $L_{t o t}$ is the total length of the machine including the stack length and the protrusion of the end winding from the iron stack in the axial direction [2-4].

\subsection{Sizing equations for the TORUS-NS:}

The generalized sizing equation approach can easily be applied to axial flux permanent magnet TORUS type motor [4]. The outer surface diameter $D_{o}$ can be written as

$$
\mathrm{D}_{\mathrm{o}}=\left(\mathrm{P}_{\text {out }} / \frac{\pi \mathrm{m}}{2 \mathrm{~m}_{1}} \mathrm{~K}_{\mathrm{e}} \mathrm{K}_{\mathrm{p}} \mathrm{K}_{\mathrm{i}} \mathrm{A} \mathrm{B}_{\mathrm{g}} \eta \frac{\mathrm{f}}{\mathrm{p}}\left(1-\lambda^{2}\right)\left(\frac{1+\lambda}{2}\right)\right)^{1 / 3}
$$

The machine total outer diameter $D_{t o t}$ for the TORUS-S motor is given by

$\mathrm{D}_{\text {tot }}=\mathrm{D}_{\mathrm{o}}+2 \mathrm{~W}_{\mathrm{cu}}$

Where, $W_{c u}$ is the protrusion of the end winding from the iron stack in the radial 
direction. For the back-to-back wrapped winding, protrusions exist toward the axis of the machine as well as towards the outsides and can be calculated as

$\mathrm{W}_{\mathrm{cu}}=\frac{\mathrm{D}_{\mathrm{i}}-\sqrt{\mathrm{D}_{\mathrm{i}}^{2}-\left(2 \mathrm{AD}_{\mathrm{g}} / \mathrm{K}_{\mathrm{cu}} \mathrm{J}_{\mathrm{s}}\right)}}{2}$

Where, $\mathrm{Dg}$ is the average diameter of the machine, $J_{s}$ is the current density and $K_{c u}$ is the copper fill factor.

The axial length of the machine $L_{e}$ is given by

$\mathrm{L}_{\mathrm{e}}=\mathrm{L}_{\mathrm{s}}+2 \mathrm{~L}_{\mathrm{r}}+2 \mathrm{~g}$

Where, $L_{s}$ is axial length of the stator, $L_{r}$ is axial length of the rotor and $g$ is the air gap length. The axial length of the stator $L_{s}$ is

$\mathrm{L}_{\mathrm{s}}=\mathrm{L}_{\mathrm{cs}}+2 \mathrm{~W}_{\mathrm{cu}}$

The axial length of the stator core $L_{c s}$ can be written as

$L_{c s}=\frac{B_{g} \pi \alpha_{p} D_{o}(1+\lambda)}{4 p B_{c s}}$

Where, $B_{c s}$ is the flux density in the stator core and $\alpha_{\mathrm{p}}$ is the ratio of average air gap flux density to peak air gap flux density. Since there is no rotor core in rotor PM topologies, the axial length of rotor $L r$ is

$\mathrm{L}_{\mathrm{r}}=\mathrm{L}_{\mathrm{PM}}$

Also, the axial length of the rotor core $\mathrm{L}_{\mathrm{cr}}$ is

$\mathrm{L}_{\mathrm{cr}}=\frac{\mathrm{B}_{\mathrm{u}} \pi \mathrm{D}_{\mathrm{o}}(1+\lambda)}{8 \mathrm{p} \mathrm{B}_{\mathrm{cr}}}$

Where, $B_{c r}$ is the flux density in the rotor disc core, and $B_{u}$ is the attainable flux density on the surface of the PM. The PM length $L_{P M}$ can be calculated as

$\mathrm{L}_{\mathrm{PM}}=\frac{\mu_{\mathrm{r}} \mathrm{B}_{\mathrm{g}}}{\mathrm{B}_{\mathrm{r}}-\left(\frac{\mathrm{K}_{\mathrm{f}}}{\mathrm{K}_{\mathrm{d}}} \mathrm{B}_{\mathrm{g}}\right)}\left(\mathrm{g}+\mathrm{W}_{\mathrm{cu}}\right)$

Where, $\mu_{r}$ is the recoil relative permeability of the magnet, $B_{r}$ is the residual flux density of the PM material, $K_{d}$ is the leakage flux factor, $K_{c}$ is the carter factor, $K_{f}$ $=B_{g p k} / B_{g}$ is the peak value corrected factor of air gap flux density in radial direction of the AFPM motor. These factors can be obtained using FEM analysis [4].

\subsection{Sizing equations for the AFIR-NS:}

The concept of Double-sided Axial Flux two-stator-one-rotor (AFIR) type PM motors was presented in [2-3]. The outer surface diameter $D_{o}$ is obtained from (6). 


$$
\mathrm{D}_{\mathrm{o}}=\left(2 \mathrm{P}_{\mathrm{out}} / \frac{\pi \mathrm{m}}{2 \mathrm{~m}_{1}} \mathrm{~K}_{\mathrm{e}} \mathrm{K}_{\mathrm{p}} \mathrm{K}_{\mathrm{i}} \mathrm{A} \mathrm{B}_{\mathrm{g}} \eta \frac{\mathrm{f}}{\mathrm{p}}\left(1-\lambda^{2}\right)\left(\frac{1+\lambda}{2}\right)\right)^{1 / 3}
$$

The machine total outer diameter $D_{t o t}$ for the AFIR type machines is given as $D_{t o t}=D_{o}+2 W_{c u}$

Where, $W_{c u}$ is the protrusion of the end winding from the iron stack in the radial direction and can be calculated as

$$
\mathrm{W}_{\mathrm{cu}}=\frac{\mathrm{D}_{\mathrm{i}}-\sqrt{\mathrm{D}_{\mathrm{i}}^{2}-\left(\mathrm{AD}_{\mathrm{g}} / \mathrm{K}_{\mathrm{cu}} \mathrm{J}_{\mathrm{s}}\right)}}{2}
$$

The axial length of the machine $L_{e}$ is

$$
\mathrm{L}_{\mathrm{e}}=\mathrm{L}_{\mathrm{r}}+2 \mathrm{~L}_{\mathrm{s}}+2 \mathrm{~g}
$$

Where, $L_{s}$ is axial length of the stator, $L_{r}$ is axial length of the rotor and $g$ is the air gap length. The axial length of a stator $L_{s}$ is

$$
\mathrm{L}_{\mathrm{s}}=\mathrm{L}_{\mathrm{cs}}+2 \mathrm{~W}_{\mathrm{cu}}
$$

Where, $L_{c s}$ is the axial length of the stator core. The axial length of the stator core $L_{c s}$ can be written as

$$
\mathrm{L}_{\mathrm{cs}}=\frac{\mathrm{B}_{\mathrm{g}} \pi \alpha_{\mathrm{p}} \mathrm{D}_{\mathrm{o}}(1+\lambda)}{8 \mathrm{pB}_{\mathrm{cr}}}
$$

Since there is no rotor core in rotor PM topologies, the axial length of rotor $L r$ is

$\mathrm{L}_{\mathrm{r}}=\mathrm{L}_{\mathrm{PM}}$

The PM length $L_{P M}$ can be calculated as

$$
L_{P M}=\frac{2 \mu_{r} B_{g}}{B_{r}-\left(\frac{K_{f}}{K_{d}} B_{g}\right)}\left(g+W_{c u}\right)
$$

\section{Comparison of TORUS-NS and AFIR-NS:}

Comparison of two different Double-sided axial flux non-slotted PM motors in terms of power density is accomplished for $10 \mathrm{HP}$ output power, 6 poles and $60 \mathrm{~Hz}$ drives. In this comparison, other constant parameters of motors are tabulated in table (1).

Table (1): Constant parameters of motors

\begin{tabular}{|l|l|}
\hline Number of phases & 3 \\
\hline Slot fill factor & 0.8 \\
\hline Pole arc ratio & 0.75 \\
\hline Slot per Pole per Phase & 1 \\
\hline flux density in stator & $1.5 \mathrm{~T}$ \\
\hline flux density in rotor & $1.5 \mathrm{~T}$ \\
\hline
\end{tabular}




\begin{tabular}{|l|l|}
\hline flux density in rotor & $1.5 \mathrm{~T}$ \\
\hline Efficiency & $90 \%$ \\
\hline PM Residual flux density & $1.1 \mathrm{~T}$ \\
\hline
\end{tabular}

In AFPM motors, the air gap flux density, $\mathrm{Bg}$ and diameter ratio, $\lambda$ and are the two important design parameters which have significant effect on the motor characteristics. Therefore, in order to optimize the motor performance, the diameter ratio and the air gap flux density must be chosen carefully.

Figure (3) shows the power density variation as a function of air gap flux density and the diameter ratio for the AFIR-NS and TORUS-NS motors.

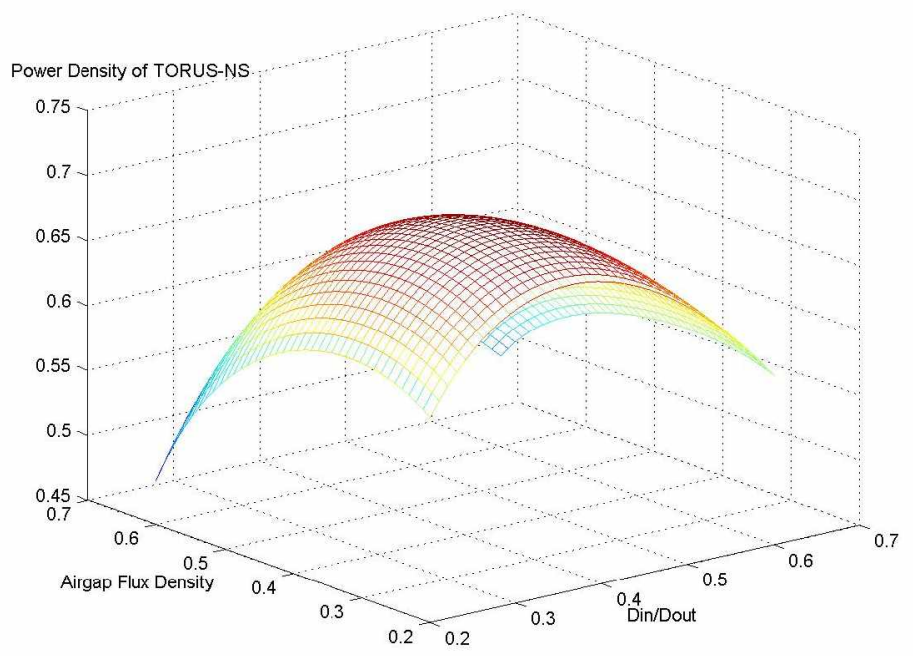

(a)

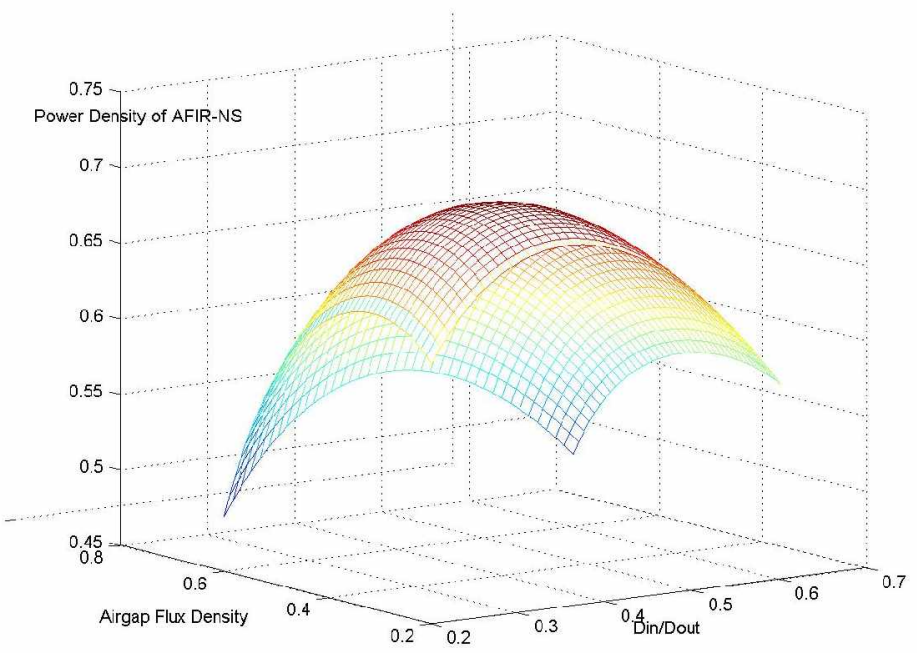

(b)

Figure (3): Power density vs. air-gap flux density and diameter ratio for $A=20000$
$(\mathrm{A} / \mathrm{m}), \quad \mathrm{g}=1(\mathrm{~mm}), \mathrm{J}_{\mathrm{s}}=6000000\left(\mathrm{~A} / \mathrm{m}^{2}\right)$
a) TORUS-NS
b) AFIR-NS 
As can be seen from figure ( $3 b$ ), the maximum power density occurs at $B g=0.312 \mathrm{~T}$ and $\lambda=0.343$. Varying air gap length, maximum power density occurs in different $\mathrm{Bg}$ and $\lambda$. Table 2 shows maximum power density with corresponding $\mathrm{Bg}$ and $\lambda$.

Table (2): Maximum power density with corresponding Bg and $\lambda$

\begin{tabular}{|c|c|c|c|c|}
\hline Type & $\begin{array}{c}\mathrm{g} \\
(\mathrm{mm})\end{array}$ & $\begin{array}{c}\mathrm{Bg} \\
(\mathrm{T})\end{array}$ & $\lambda$ & $\begin{array}{c}\text { Maximum power } \\
\text { density }\left(\mathrm{W} / \mathrm{cm}^{3}\right)\end{array}$ \\
\hline \multirow{3}{*}{ TORUS-NS } & 1 & 0.323 & 0.353 & 0.705 \\
\cline { 2 - 5 } & 1.5 & 0.321 & 0.352 & 0.680 \\
\cline { 2 - 5 } & 2 & 0.320 & 0.351 & 0.650 \\
\hline \multirow{3}{*}{ AFIR-NS } & 1 & 0.312 & 0.343 & 0.706 \\
\cline { 2 - 5 } & 1.5 & 0.308 & 0.341 & 0.680 \\
\cline { 2 - 5 } & 2 & 0.302 & 0.340 & 0.650 \\
\hline
\end{tabular}

Figure (4) shows the maximum power density variation as a function of air gap length for the AFIR-NS and TORUS-NS motors for $A=20000(\mathrm{~A} / \mathrm{m}), \mathrm{Js}=6000000\left(\mathrm{~A} / \mathrm{m}^{2}\right)$. In as special air gap length (this air gap length is called Gs) maximum power density of AFIR-NS and TORUS-NS motors will be the same. Considering figure (4) it can be concluded that in large air gap length, non-slotted TORUS motor has high power density.

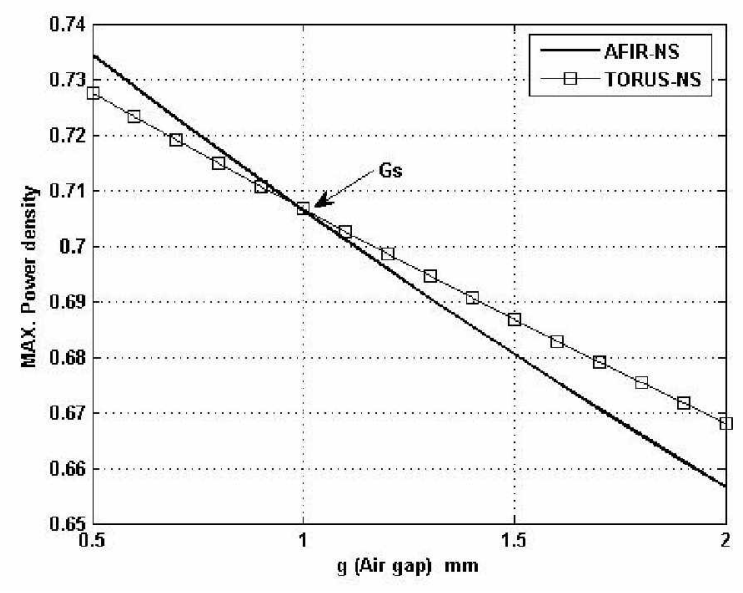

(4)

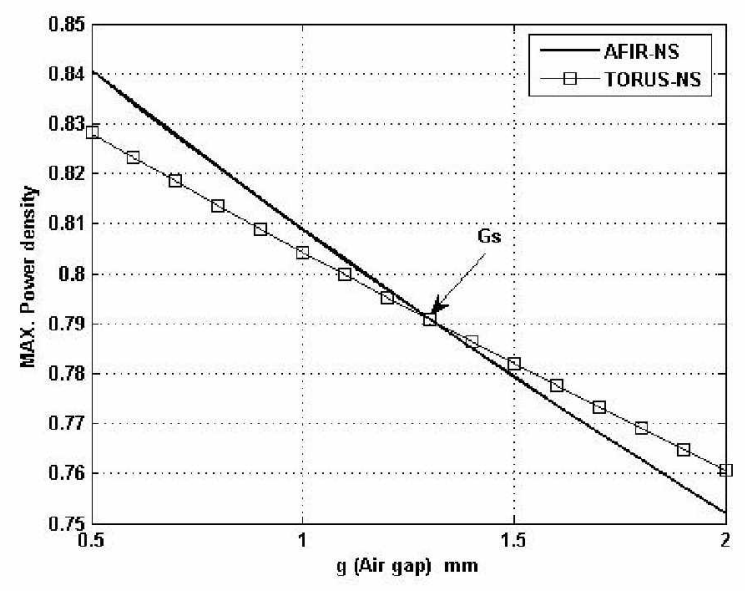

(5)

Figures (4-5): maximum power density AFIR-NS and TORUS-NS vs. air-gap length

The considerable point is that the value of Gs will vary when the electrical loading 'A' and current density 'Js' changes. Figure (5) shows the maximum power density variation as a function of air gap length in $\mathrm{A}=25000(\mathrm{~A} / \mathrm{m})$ and $\mathrm{J}_{\mathrm{s}}=6000000\left(\mathrm{~A} / \mathrm{m}^{2}\right)$ for the AFIR- 
NS and TORUS-NS motors.

Figure (6) shows the maximum power density variation as a function of air gap length in $\mathrm{A}=20000(\mathrm{~A} / \mathrm{m})$ and $\mathrm{J}_{\mathrm{s}}=7000000\left(\mathrm{~A} / \mathrm{m}^{2}\right)$, for the AFIR-NS and TORUS-NS motors also.

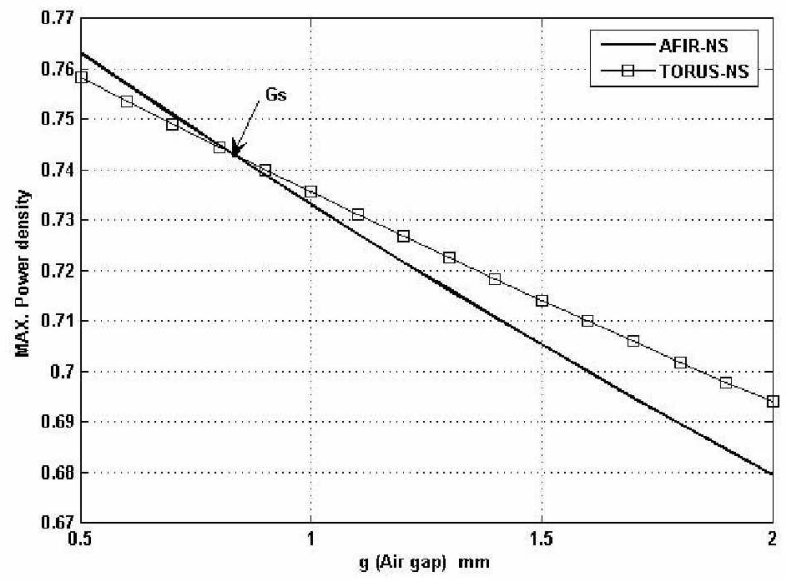

Figure (6): maximum power density AFIR-NS and TORUS-NS vs. air-gap length

According to Figure (5) it can be concluded that point Gs is shifted to larger air gaps and this means that in smaller air gaps AFIR-NS motor has higher maximum power density. According to Fig.6 it can be concluded that point $G s$ is shifted to smaller air gaps and this means that in higher air gaps TORUS-NS motor has higher maximum power density. Other value of $G s$ for various A and Js are tabulated in table (3).

Table (3): Other value of Gs for Various A and Js

\begin{tabular}{|c|c|c|}
\hline $\mathrm{A}$ & Js & Gs (mm) \\
\hline 20000 & 6000000 & 0.97 \\
\hline 22000 & 6000000 & 1.1 \\
\hline 25000 & 6000000 & 1.3 \\
\hline 30000 & 6000000 & 1.67 \\
\hline 20000 & 6500000 & 0.89 \\
\hline 20000 & 7000000 & 0.82 \\
\hline 20000 & 8000000 & 0.7 \\
\hline 20000 & 90000 & 0.62 \\
\hline
\end{tabular}

\section{Conclusions:}

Selecting an AFPM motors with higher power density is an important parameter in applications. The main goal of this paper has been introducing to double-Sided Axial Flux non-slotted PM Motors with maximum power density. There are two topologies 
for NON-slotted double-sided AFPM motors.

The maximum power density is changed by different value of the air gap, electrical loading and current density. TORUS-NS topology has high power density in high current density and low electrical loading. But, AFIR-NS topology has high power density in low current density and high electrical loading.

\section{References:}

[1] S. Huang, J. Luo, F. Leonardi, and T. A. Lipo, “A General Approach to Sizing and Power Density Equations for Comparison of Electrical Machines," IEEE Trans. On Energy Conversion, IA-34, No.1, pp.92-97, 1998.

[2] S. Huang, J. Luo, F. Leonardi and T. A. Lipo, "A Comparison of Power Density for Axial Flux Machines Based on the General Purpose Sizing Equation", IEEE Trans. on Energy Conversion, Vol.14, No.2 June 1999, pp. 185-192.

[3] Aydin, M.; Huang, S.; Lipo, T.A.; "Optimum design and 3D finite element analysis of nonslotted and slotted internal rotor type axial flux PM disc Machines", Power Engineering Society Summer Meeting, 2001. IEEE Volume 3, 15-19 July 2001 Page(s):1409 - 1416 vol.3.

[4] Aydin, M.; Surong Huang; Lipo, T.A.; "Design and 3D electromagnetic field analysis of non-slotted and slotted TORUS type axial flux surface mounted permanent magnet disc machines", Electric Machines and Drives Conference, 2001. IEMDC 2001. IEEE International2001 Page(s):645 - 651. 